\title{
Editorial: HJD Fifteen Years on, Past and Present Board Members on Future Research
}

It is fifteen years since the first issue of The Hague Journal of Diplomacy (HJD) appeared in 2006. To mark the occasion, we have put together an editorial on where diplomacy, diplomatic studies and HJD might be going. In the first editorial heading up the inaugural issue in 2006, we noted 'possibly excessive worries' about the foreign policy of the United States, the future of the European Union, and the conduct of what was still known then as the 'War on Terror'. How times don't change! We considered re-running the first editorial, only with 'possibly excessive' suitably replaced. However, perhaps it is only people interested in diplomacy who might be tempted to characterise the present in terms of Martin Wight's 'same old melodrama'. We decided to ask current and former members of HJD's International Advisory Board for their takes on what is, will and ought to be happening in diplomacy and diplomatic studies. Here are the results.

To begin, nearly everyone has nice things to say about how the journal has helped to raise the profile of diplomacy in the academic study of International Relations (IR). As Markus Kornprobst (Austria) expresses it, some of the most exciting areas in IR research today - micro-sociology, cognitive studies and inquiries into digital communications - use diplomacy both broadly and narrowly defined as their field of study. Alisher Faizullaev (Uzbekistan) notes that $H J D$ has not only contributed to raising awareness about diplomacy, but also to the wider application of diplomatic thought and action in the world beyond state-to-state relations. As Geoffrey Wiseman (Australia) points out, however, the birth of the journal coincided with other developments that gave a boost to the study of diplomacy, most notably the creation of a diplomatic studies section of the US-based International Studies Association.

A clear theme that emerged was the need for HJD and diplomatic studies to engage more closely and explicitly with the great changes taking place in the world at the moment. Good diplomats seek to finesse the worst consequences of politics gone bad. Diplomacy itself, however, is an intensely political activity, although you might not realise this after reading pages devoted to diplomacy presented as the management and organisation of techniques of international problem-solving. Chen Zhimin (China) expresses this call for 
closer engagement directly in terms of the challenge to diplomacy posed by the United States' successive focuses on policies of military and economic coercion. Kishan Rana (India) stresses the cultural dimension of this change and specifically the accelerating decline of Western influence and values as a global force, as China, India and others continue to rise. Christer Jönsson (Sweden), in contrast, asks for more attention on the threat to democracy posed by contemporary populism. Contemporary politics badly need an injection of the virtues traditionally associated with diplomacy, for example maintaining civility, exercising a sense of systemic responsibility, and being predisposed to livingand-letting-live. Scholars and diplomats have a responsibility to advocate for these virtues where they can.

As to the future of diplomacy itself and how we study it, familiar but important themes emerge. Constance Duncombe (Australia) notes the growing recognition of gender in diplomatic studies and practice. The continuing proliferation of both types and numbers of diplomatic actors appears in several of the responses. Brian Hocking (UK) suggests, however, that this presents increasing problems regarding diplomatic standing and diplomatic credentialing, which governments, their professional foreign services and many who study diplomacy remain leery about facing. Two countervailing trends are also noted. The first is the continued rise of presidential diplomacy, made, as Alan Henrikson (US) notes, both more prominent and more problematic by President Trump's use of social media and the importance he assigns to the spectacle of highly mediated diplomatic situations. The second, however, is the set of problems presented by the involvement of more actors, as various colleagues noted, and newly influential old ones, such as missions participating through real-time contact with headquarters, in the policy process. The old question from an executive perspective was how to control and coordinate these actors. The new question, Henrikson says, is how to get 'buy in' from agencies who cannot be controlled but whose cooperation is needed. A future question, at least in the case of the United States, as noted by Mai'a Davis Cross (US), is how a diplomatic system is to function under a political leadership that appears committed to effecting change by starving the bureaucratic beast.

Even as diplomatic services wrestle with established challenges and diplomatic scholars study their efforts, new challenges are proliferating in terms of both processes and issues. In terms of the former, Davis Cross calls for more attention to policy planning through future studies and scenario-modelling. In terms of the latter, she asks what the impact of robotics, artificial intelligence and biotechnology will be. If they call into question our understandings of ourselves and what it means to be human, then surely they also call into question 
how we communicate with one another and our understandings of what is going on when we communicate.

That a request for reflections on the present and future of diplomacy can lead to such wide-ranging speculations is one of the great attractions of studying diplomacy. Conceivably, however, it is also symptomatic of a weakness made explicit by asking two old questions in diplomatic studies: what are we studying, and why are we studying it? Old and narrow answers built around the relations of states undertaken by their officially accredited representatives no longer serve - at least in the sense that these, and only these, should be regarded as diplomacy. If, however, we take a broader approach that suggests, in principle at least, that the full spectrum of human relations provides us with our canvas, then this raises the question of why we try to access and interpret those relations through framings suggested by diplomacy.

This is a difficult question to answer, although from some perspectives it may not be important that we try. If, for example, one regards diplomacy as a historically contingent practice, emerging within the ways of thinking at a particular time and place, then it may be a way of conducting relations that are not merely changing but disappearing. If so, however, then it is a strange disappearance, much like Realism's disappearance from IR. You can look over the stern, see the wake marking our journey away from it on the horizon, and then you notice that instead of receding, it maintains the same distance away from us.

Practice theory provides a different kind of answer to why we study diplomacy - one that both burnishes and dims its significance at the same time. Diplomacy is the stuff of international relations - both the production and the thing produced. Look at real people doing international relations and what they actually think and say as they do them. This is the burnishing part that has brought the study of diplomacy into the heart of IR. The dimming part follows swiftly, however, for there is no diplomacy in some sort of essential, objective sense as a way of conducting relations, any more than there are states, balances of power, national interests, or all the IR concepts that exist only insofar as they are in the heads and shape the actions of people doing both international relations and International Relations. The result is that we are enjoined to look at diplomats - for what they do, for what they say, for what they tell us they think and, perhaps, for chinks of daylight between them but without any sense of a master narrative or meta-narrative emerging to guide us towards a claim, for example, as to 'and here's why we look at diplomacy' or 'and here's why diplomacy well or badly done matters'.

To be fair to most practice theorists, generating narratives about the importance of diplomacy is not what they are trying to do. Indeed, they are inclined 
to think that people who generate such narratives generally import their own meta-baggage into the subject and, as such, are engaged in unhelpful and problematic activity.

With regard to the future direction of the journal itself, two themes emerge from the reflections of the scholars on our Advisory Board. The first is that we need to engage in continuous reflection on how the review process works and, particularly, communicating expectations to reviewers about what they should be doing, what is helpful to both editors and authors, and what is not. From an editor's perspective, this is enormously useful advice.

Second, both scholar-practitioners who responded, Kishan Rana (India) and Iver Neumann (Norway), suggest that now that the study of diplomacy has been put on a firm academic footing, it might be time to go beyond the single practitioner's piece that appears in most issues of HJD. More space, they both note, should be given to what diplomats have to say about their profession and practice. This is an important suggestion, although an old difficulty that we continue to face is that practitioners often want to talk about world politics generally, rather than to reflect closely on their own experiences of doing diplomacy. That said, this is a good argument for pairing up the best scholarly research in our academic journal with professional perspectives.

\section{Paul Sharp and Jan Melissen}

Co-editors

Constance Duncombe and Marcus Holmes

Associate Editors 